\title{
Benevolence and the value of road safety*
}

\author{
Henrik Andersson ${ }^{1,2, \star \star}$, Gunnar Lindberg ${ }^{2}$ \\ 1 Toulouse School of Economics (LERNA), Toulouse, France \\ 2 Department of Transport Economics, Swedish National Road and Transport Research Institute (VTI), \\ Stockholm, Sweden
}

December 4, 2008

\begin{abstract}
This study uses the contingent valuation method to elicit individuals' preferences for their own and others' safety in road-traffic. Whereas one group is asked about a private safety device for themselves, other groups are asked about safety devices for their children, household, relatives and the public. Support is found for the hypothesis that individuals are not purely selfish when it comes the safety of others.
\end{abstract}

Key words Safety; Willingness to pay; Altruism; Road-traffic

JEL codes: D61, D64, H51, I10

* The authors would like to thank Lars Hultkrantz, Jan Owen Jansson, Olof Johansson-Stenman, and Mikael Svensson for valuable comments on earlier drafts of this paper. Financial support from Banverket, Vinnova, and Vägverket is gratefully acknowledged. The authors are solely responsible for the results presented and views expressed in this paper.

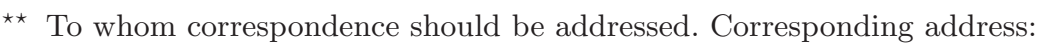
Toulouse School of Economics, 21 all.de Brienne, Aile J.J. Laffont, 31042 Toulouse, France, e-mail: henrik. andersson@tse-fr.eu 


\section{Introduction}

The scarcity of resources forces policy makers to prioritize between policies. To secure an efficient resource allocation benefit-cost analysis (BCA), in which the social benefits of a policy or investment are compared to its costs, is often used. The monetary value of reducing road mortality risk is usually (together with the monetary value of reduced travel time) one of the dominating components of the benefit side in BCA of transport investments and policies. ${ }^{1}$ This study examines preferences for safety and in conventional BCA the monetary benefit measure of reducing mortality risk, the value of a statistical life (VSL), is based on the preferences of purely self-interested individuals. In many cases, as pointed out by, e.g., Becker (1976) and Sen (1987), it is clear that people do not act only as self-interested individuals but in a context of social interaction, and if individuals are not purely self-interested but also concerned about the safety of others, it would seem reasonable, and has been argued, that the value of safety should be augmented by an amount that reflects this altruistic component (Mishan, 1971; Jones-Lee, 1976; Needleman, 1976).

Bergstrom (1982) showed, however, that when individuals can be characterized as pure (or nonpaternalistic) altruists, their VSL will be identical to the VSL derived under pure self-interest. ${ }^{2}$ Hence, he showed that it will be inappropriate to include an altruistic component in the VSL, and willingness to pay (WTP) for others' safety should be ignored in BCA. ${ }^{3}$ Jones-Lee $(1991,1992)$ extended the analysis and proved that Bergstrom's result is also valid when preferences are purely paternalistic, but when preferences are safety-paternalistic (cares only about the safety argument in the utility function of others) benevolence should be considered in BCA. Since whether VSL should be augmented or not depends on the form of altruism, and the benefits of reducing the risk can be decisive for the outcome of a BCA, it is important not only to study the magnitude of non-selfishness, but also the form it takes.

Several studies have empirically examined individuals' WTP for others' safety (health). For instance, there is empirical evidence which implies that individuals are safety-paternalistic (Vázquez Rodríguez and León, 2004; Jacobsson et al., 2007; Holmes, 1990). Moreover, Liu et al. (2000), Dickie and Messman (2004) and Chanel et al. (2005) found that mothers and parents were willing to pay more for the safety of their children than for their own safety, Dickie and Gerking (2007) that parents were paternalistic altruists towards their children, and Bateman and Brouwer (2006) and Chanel et al. (2005) that WTP

\footnotetext{
1 Persson and Lindqvist (2003) showed for Sweden that approximately half of the benefits to society of road projects can be attributable to increased traffic safety.

2 Non-paternalistic preferences require that "each individual respect the tastes of others, no matter what he thinks of them" (Archibald and Donaldson, 1976, p. 494). A pure paternalist, on the other hand, is concerned about others but ignores their preferences.

3 The argument that pure altruistic preferences can be ignored in BCA was generalized in Bergstrom (2006)
} 
for the entire household is larger than individual WTP. ${ }^{4}$ However, Leung and Guria (2006) found the opposite for household WTP, with single household having the highest WTP and inconclusive results regarding WTP for child safety. It also seems that most of the empirical evidence shows that individuals are not prepared to pay as much for a public safety measure as for a private measure, even though there is also evidence of the opposite (Viscusi et al., 1988; Johannesson et al., 1996; Araña and León, 2002; de Blaeij et al., 2003; Hultkrantz et al., 2006). Hence, the overall evidence regarding altruism seems inconclusive.

The aim of this study is to further contribute to the empirical analysis of altruism and safety. We explore the domain of selfish and non-selfish safety preferences in a set of questions on road safety, and the safety impact of our good extends from purely private impacts, to impacts on children, the whole household, to relatives and friends and is finally defined as a public good. In order to elicit the preferences for reducing road risk we use the contingent valuation method (CVM) on a Swedish sample. ${ }^{5}$ Due to the public good characteristic of many public safety programmes and the fact that traffic safety may be achieved through both public programmes and private provision, it is interesting to examine safety both as a private and a public good. By examining respondents' WTP for different devices (public/private) and for own and others' safety, we may draw conclusions regarding individuals' altruistic preferences.

In the following sections 2,3 , and 4 we describe the theoretical framework, how the survey was conducted, the design of the questionnaire, and the empirical models. Section 5 contains the results. Our results indicate that the respondents of our survey are not purely selfish, but are prepared to pay for the safety of children, relatives and friends. Given that people show strong concern for their relatives' and friends' safety, we may expect that safety for a public safety measure is valued higher than a private safety device. We find, however, that WTP for the public good is significantly lower compared with the private good. We discuss our findings and draw some conclusions in section 6 .

\section{The theoretical framework}

The theoretical model in this section, due to Jones-Lee $(1991,1992)$ and Johannesson et al. (1996), is a single-period model in which individuals face two possible outcomes; staying alive or being dead. Let $V_{i j}(),. \pi_{i j}$, and $y_{i j}$ denote a well-behaved utility function (see, e.g., Varian, 1992), survival probabilities,

\footnotetext{
4 Depending on elicitation format, Bateman and Brouwer (2006) only found weak support for their hypothesis. See also Bateman and Brouwer (2006) for references to other studies that have found a higher value of WTP for child safety.

${ }^{5}$ In the CVM respondents are asked to state their WTP for a non-marked good, e.g. wildlife protection, increased air quality, or as in this a reduction in mortality risk. The CVM is a stated-preference technique, i.e. respondents' preferences are elicited in a hypothetical setting. For a description of CVM see, e.g., Mitchell and Carson (1989) or Bateman et al. (2002).
} 
and wealth, respectively. For simplicity we assume a model with only two individuals and the subscript $i=\{1,2\}$ refers to the individuals with 1 defining the considered individual. The second subscript $j=\{0,1\}$ refers to before (0) and with (1) the safety project, with $\pi_{i 0}<\pi_{i 1}$. Our utility function can now be written as follows:

$$
V_{10}=V_{10}\left(\pi_{10}, y_{10}, \pi_{20}, y_{20}\right)
$$

which is assumed to be strictly increasing in $\pi_{1 j}$ and $y_{1 j}$, and non-decreasing in $\pi_{2 j}$ and $y_{2 j}$. We consider the following cases where the considered individual is: (i) purely selfish if $\partial V_{1 j} / \partial \pi_{2 j}=0$ and $\partial V_{1 j} / \partial y_{2 j}=$ 0 , (ii) a pure altruist if both are strictly positive and the preference of others are respected ${ }^{6}$, (iii) a pure paternalist if again both are strictly positive but others' preferences are disregarded, and (iv) a safety paternalist if $\partial V_{1 j} / \partial \pi_{2 j}>0$ and $\partial V_{1 j} / \partial y_{2 j}=0$. In the last case the individual only cares about one aspect regarding others' well-being, i.e. safety. If, on the other hand, the individual only cares about others' wealth levels, he/she would be wealth paternalistic.

We start by deriving WTP for a private and a public safety measure following the analysis in Johannesson et al. (1996). Both safety measures affect individuals in the same way, the difference being the characteristic of the good and the way it is financed. The private good is paid for by the individual, whereas the public good is financed through a lump-sum tax. The optimization problems can be written as follows:

$$
\begin{aligned}
V_{11}\left(\pi_{11}, y_{10}-p_{1}, \pi_{20}, y_{20}\right) & =V_{10}, \\
V_{11}\left(\pi_{11}, y_{10}-t_{1}, \pi_{21}, y_{20}-t_{1}\right) & =V_{10},
\end{aligned}
$$

where $p_{1}$ in Eq. (2) refers to WTP for the private risk reduction and $t_{1}$ in Eq. (3) is the WTP for the public safety measure. A selfish and a safety paternalistic individual would report $t_{1}=p_{1}$ and $t_{1}>p_{1}$, respectively. Whereas a pure altruist who believes that $t_{1}$ approximates the WTP of the other individual would report $t_{1}=p_{1}$ (since $i=2$ remains at his/her initial utility), if he/she believes that the project will increase (reduce) the other person's overall wellbeing he/she would state $t_{1}>(<) p_{1}$.

We now turn to different scenarios where we examine an individual's WTP for a private good safety device that will increase the survival probability of someone else. Let $p_{2}$ denote our considered individual's WTP for a safety device for $i=2$, and the optimization problem may now be written as:

\footnotetext{
${ }^{6}$ For a pure altruist, $\left(\partial V_{1 j} / \partial \pi_{2 j}\right) /\left(\partial V_{1 j} / \partial y_{2 j}\right)=\left(\partial V_{2 j} / \partial \pi_{2 j}\right) /\left(\partial V_{2 j} / \partial y_{2 j}\right)$, since he/she respects the preferences of others.
} 


$$
V_{11}\left(\pi_{10}, y_{10}-p_{2}, \pi_{21}, y_{20}\right)=V_{10}
$$

It can be shown that $p_{2}>0$ when individual 1 is a safety paternalist, a pure altruist or paternalist.

Using Eq. (4) we can also examine intra-household WTP, where we assume that the second individual is a child with zero wealth, i.e. $y_{2}=0$. Thus, in this scenario $y_{1}$ is the household's wealth level and we assume that the child's consumption comes from the wealth of the parent and that expenditures for the child's risk reduction will be borne by the parent. Unless the parent is wealth paternalistic, $p_{2}>0$. It can also be shown that $p_{2}$ is the largest when the parent is safety paternalistic. Whether $p_{2} \gtreqless p_{1}$ depends on the parent's preferences for the safety of his/her child. Finally, let $p_{h}$ define household WTP $\left(p_{1}+p_{2} \equiv p_{h}\right)$. When both individuals experience an increase in survival probability, Eq. (4) also implies that $p_{h}>p_{1}$ for a safety paternalist or a pure altruist or paternalist.

\section{Contingent valuation survey}

The survey was conducted in the city of Örebro by mail in 1998. Prior to the main survey a pilot was used to decide on the bid levels. The sample in the main survey consisted of 1,950 individuals between 18-76 years of age, and after two reminders the response rate was 55 percent. The sample was split into five groups in order to examine how the respondents' WTP was affected by which of the following subjects benefited from the safety measure: (i) own, (ii) child, (iii) household, (iv) relatives and friends, and (v) the public. The safety measure for the first four groups was a private good, but a public one in the last subsample. The group that received the question on child safety consisted of households with at least one child younger than 18; addresses to these households were in the mother's name. ${ }^{7}$

In order to mitigate the well known problem of individuals' judgement of small probabilities , including perception of mortality risk, and to make the safety measure more understandable, the risk reduction was presented as an elimination of fatalities and severe injuries in road-traffic (Kahneman and Tversky, 1979; Kahneman et al., 1982; Hakes and Viscusi, 2004; Andersson and Lundborg, 2007). An elimination (in the long run) of fatalities and severe causalities in road-traffic is a national aim of the Swedish transport policy (Vision zero (Prop. 1997/98:56, 1998)), an aim that has received a lot of attention in the Swedish media. The city of Örebro was chosen for the survey, since the municipality has prepared a traffic safety programme in accordance with Vision zero. This has also been covered in the local press, and we, therefore, believe that a scenario with zero fatalities and severe injuries (in accordance with

\footnotetext{
7 Addresses for this kind of household were only available in the mothers' names, which is why questionnaires were only sent out to women.
} 
Vision zero) is credible for the people of Örebro. The same risk scenario to elicit WTP was used in Hultkrantz et al. (2006).

\subsection{Questionnaire}

All questionnaires included information about the number of fatalities and severe injuries in Örebro during 1996 and 1997 and the mean for the period 1993 to 1997, the distribution of the fatalities and severe injuries between modes of transport in a pie-chart, and the actual location of the last year's accidents on a town map. ${ }^{8}$ The annual risk was communicated to the respondents in the following way:

Örebro has approximately 120,000 inhabitants. In a group of 10,000 inhabitants, around 2 persons will be killed or severely injured annually in urban traffic if the safety situation is not improved.

[Table 1 about here.]

The five subsamples are found in Table 1 together with sample sizes and response rates. In questionnaires Q1-Q4 the safety measure was a private good, whereas in Q5 it was a public good. Both goods were abstract safety devices reducing the risk to zero. The private safety device would reduce the risk to zero for the user of the device and could be rented on an annual basis. The subsample that was asked about a device for themselves (Q1 Private) is used as the reference group in our study and it was presented with the following scenario:

"Assume that a traffic safety device is developed to reduce the fatality and severe injury risk to zero within an urban area, e.g. Örebro. The device may be used by pedestrians, cyclists, and motorists. The device may be rented annually and reduces the risk to zero, as mentioned, but only for the users of the device; it cannot be shared by others. Remember that the rent has to be paid with the annual income of the household."

The respondents were then asked whether they were willing to pay a given price for the safety device, i.e. a single bounded dichotomous choice questions:

Would you rent the device for your own use for SEK 200 per year?

In total six bid levels were used, $\operatorname{Bid}=\{200 ; 1,000 ; 2,000 ; 5,000 ; 10,000 ; 20,000\}$, where the levels were based on the results of the pilot study. ${ }^{9}$

\footnotetext{
8 The average number of fatalities and severe injuries between 1993-1997 was 3 and 16, respectively. The distribution of accidents with severe or fatal outcome was (percent); bicycle 66, car 21, pedestrian 10, moped 2 and motorcycle 1 .

9 Monetary values in Swedish kronor (SEK) in 1998 prices. USD $1 \approx$ SEK 8
} 
The other groups that were asked about the private device (Q2-Q4) were asked similar questions that had been adjusted to fit each scenario. For instance, in Q2 Child the safety device was to be used by one of the respondent's children younger than 18 and living at home. Moreover, in the question about household safety (Q3 Household), the respondent was asked about a device that would reduce the risk for all members of the household. In the question about total household safety, the bid levels above were doubled, since respondents were asked about a safety device that would reduce the risk for more than one person.

In addition, two subsamples were asked about their willingness to purchase a similar device for a relative or a friend (Q3 and Q4). The subsample Q3 Household was asked about a safety device for a relative/friend after being asked about household safety, whereas Q4 Relative was only asked about a safety device for a relative/friend, this in order to simplify the task (which also eased the budget constraint). Both subsamples were also asked about the number of devices they were prepared to purchase. The scenario was as follows (Q3 Household):

"Assume that you can rent one similar device for someone outside the household (e.g. a relative or a friend). The device can be used where the person lives. The person has not received and will not receive the offer to rent such a device. You have to pay the rent and cannot demand compensation from the person."

Would you rent the device to someone outside the household (relatives or friends) for SEK 200 per year and person?

"Assume that you got the opportunity to rent additional devices for the same cost (SEK 200 per year and person)."

Would you rent more devices? (0;1;2-10;>10)

Figure 1 describes the questionnaire scheme for relatives' safety (Q3 and Q4). In both questionnaires, only respondents who were willing to rent the device for relatives were asked if they were prepared to buy their relatives a voucher for free consumption. The purpose of the follow-up question was to be able to distinguish between pure altruistic or paternalistic preferences and safety paternalistic preferences. Respondents who are safety paternalists will not answer yes to the follow-up question which was presented as follows:

"If you answered yes to the question to rent a device for one person outside the household (relative or friend) for SEK 200 per year, what is your response to the following: Instead of the safety device you can purchase a voucher for SEK 200 per person; he/she can then choose to rent the safety device for one year or use it for some other purpose that he/she would prefer." 
Would you buy a voucher for someone outside the household (relative or friend) for SEK 200 per year and person?

[Figure 1 about here.]

The public good (Q5 Public) was an unspecified safety program and the respondents were assured it would not affect their freedom to choose the transport mode, the quality of the trip, speed or the urban environment. The payment vehicle for the public good was an annual fee earmarked for a traffic safety fund within the municipality. It was highlighted that all other individuals within the municipality also had to pay the fee. This subsample was asked the following question:

Would you pay SEK 200 per year to a traffic safety fund in the municipality to ensure that this programme was introduced in Örebro?

\section{Empirical models}

We analyze our data using both non-parametric and parametric estimation techniques. For the nonparametric estimation we use the Turnbull lower bound (TB) estimator of WTP (Turnbull, 1976). ${ }^{10}$ Let $w_{j}$ and $F\left(w_{j}\right)$ denote the bid and the the proportion of no answers to the offered bid. Based on the assumptions that no respondent has a negative or infinitive WTP, i.e. $F(0)=0$ and $F(\infty)=1$, TB mean WTP is estimated by

$$
E_{T B}[W T P]=\sum_{j=0}^{J} w_{j}\left(F\left(w_{j+1}\right)-F\left(w_{j}\right)\right),
$$

where $F\left(w_{j}\right)$ should be weakly monotonically increasing. When $F\left(w_{j}\right)$ is non-monotonic, the pooled adjustment violators algorithm (PAVA) needs to be used prior to the estimation of Eq. (5) (Turnbull, 1976; Ayer et al., 1955).

When analyzing the data in the parametric model we assume a standard logistic distribution of the acceptance probability $(\Phi)$ of the bid for the risk change from $\pi_{0}$ to $\pi_{1}$ :

$$
\Phi=\left[1+e^{-\Delta v}\right]^{-1}
$$

where $\Delta v$ is the expected change in the utility level following from the safety improvement. To examine the acceptance probability we use a logit model.

Let $X$ denote a vector of other covariates of the model. When the safety device is a private commodity we can rule out negative WTP (purchase is voluntary) and estimate the mean WTP $(\bar{w})$ as the area

10 This estimator is also known as the Kaplan-Meier estimator (Carson and Hanemann, 2005). 
under the survival function for non-negative WTP values (Johansson, 1995). For the multivariate case mean WTP is estimated as:

$$
\bar{w}=\int_{0}^{\infty}\left[1+e^{\alpha+\beta w+X \Gamma}\right]^{-1} d w=-(1 / \beta)\left[\ln \left(1+e^{\alpha+X \Gamma}\right)\right] .
$$

where $\alpha, \beta$, and $\Gamma$ denote the constant, the coefficient of the bid, and a parameter vector of the other covariates in the logit regression. Mean WTP for the different safety measures is evaluated by running separate regressions for the subsamples, and then using the same values (the means of the pooled sample) for the variables of $X$. This way we account for differences of the subsamples, but mean WTP is estimated for an "identical representative individual". In order to examine the effect of both the safety measure and respondent characteristics on WTP, we also run a regression on the pooled sample. We choose the bid-function approach, developed by Cameron (1988), instead of the utility-function approach (Hanemann, 1984) for the pooled regression. The reason for choosing the bid-function approach, is because its coefficients show the covariates marginal effect on WTP, which we believe are of more interest to the readers than their effect on utility. ${ }^{11}$

\section{Results}

\subsection{Descriptive statistics}

In addition to follow-up questions on background characteristics of the respondents, the questionnaire also included questions on the travel patterns of the respondent and his/her household (car mileage, car and bus trips in Örebro, distance walking and cycling) and risk perception. The descriptive statistics for variables used in this study are presented in Table 2.

[Table 2 about here.]

We used a qualitative measure for respondents' risk perception (lower, same, or higher risk compared to the average). As shown in Table 2, 5 and 17 percent stated that their risk was higher and lower, respectively, than the average in Örebro. Thus, almost 80 percent perceived their risk to be the same as the average. If we compare this to an objective risk estimate, which is based on the respondents' own travel pattern together with objective risk estimates for the different modes, the average of the estimated objective risks in the sample is close to the objective average risk in the city, 19.6 compared with 20 per $100,000 .{ }^{12}$ Moreover, the respondents were asked about injury experience as a result of road accidents and whether they used luminous tags (an object that is worn by pedestrians in the dark to reflect the

\footnotetext{
11 This section has been kept to a minimum. For a more comprehensive description of statistical analysis, see, for instance, Hanemann and Kanninen (1999) or Haab and McConnel (2003).

12 The estimation of the objective risk can be found in Lindberg (2006).
} 
head-light of vehicles). More than half of the respondents (54 percent) stated that they themselves or someone close to them had been injured as a result of a traffic accident, and over half of the respondents used luminous tags (56 percent).

The descriptive statistics for the different subsamples reveal similar results. The only group that differs from the others is Q2 Child; in this group almost all respondents are women (questionnaire was mailed to the mother), number of children in the household is larger, household income is higher, and respondents are younger. Regarding the whole sample, compared with the general Swedish population, the respondents in the sample are slightly younger, with females overrepresented, and drive more on average (for references, see Andersson, 2007b). Disposable household income is also higher in the sample compared to the general Swedish population (ca. 12 percent, www.scb.se, 3/10/08).

\subsection{Acceptance probability and willingness to pay}

The results on probabilities of accepting bids for the different subsamples are shown in Table 3. For the majority of the questions the probabilities are non-increasing with increased bid-level. However, in Q1 and Q4 the proportion of yes answers is non-monotonic with increased bid-levels. The distributions of Table 3 also reveal that to change the safety device for a voucher was only accepted for smaller bid levels.

[Table 3 about here.]

Table 4 shows the result of the follow-up question to the question about relatives' safety. Of the respondents that wanted to rent at least one device for relatives, over half were prepared to rent more devices. The benevolence goes beyond one and may involve ten or more persons. Between 19 (Q3) and 24 (Q4) percent were prepared to pay the price for a device for the use of relatives or friends. Of these, 14 (Q3) and 18 (Q4) percent were prepared to buy a voucher for their relative's free consumption, instead of the safety device. The question on the voucher was made conditional on a yes response to the question on relative's safety device, and thus, only 2.7 (Q3) to 4.3 (Q4) percent of the sample were willing to pay for the safety device and change it for a voucher for free consumption.

[Table 4 about here.]

Non-parametric and parametric mean WTP and WTP ratios are shown in Table $5 .{ }^{13}$ We derive valuation ratios by relating the WTP for the different subsamples to WTP for Q1 Private. We observe that: (i) child safety is valued twice and three times as high as private safety in the Turnbull and

\footnotetext{
13 The results of the multivariate regressions to estimate the parametric mean WTP have been omitted from the paper, but are available upon request from the authors. The same explanatory variables as in Table 6 were used in these regressions.
} 
parametric model, respectively, (ii) household safety is valued 70 to 85 percent higher than private safety, (iii) safety for relatives and friends is valued between 33 and 51 percent of private, and (iv) WTP for the public good is 33 to 57 percent of the WTP for the private good. Whereas we can reject our hypothesis of equal means for our Turnbull estimates, only the parametric mean of subsample Q2 is statistically significantly different from Q1 Private.

[Table 5 about here.]

The results of the regression on the pooled sample are shown in Table 6 . The subsample that was asked about a private safety device (Q1) is the reference group of the subsamples. The results reveal that WTP for child and household safety is statistically significantly higher than for own safety, whereas WTP for safety for relatives and friends and a public safety measure is statistically significantly lower. Statistical tests also showed that the coefficient estimates of the different subsampels were significantly different (p-value $<0.01$ ), with one exception Q4 Relative and Q5 Public. Regarding the other covariates we find that WTP is increasing with household income but decreasing with the number of adults in the household, and higher and lower among respondents with accident experience and perceived risk lower than the average, respectively. ${ }^{14}$

[Table 6 about here.]

\subsection{Value of statistical cases}

The respondents' WTP reflect their preferences to reduce the risk of both fatalities and severe injuries. This value can be converted to the value of a severe statistical injury (VSSA) by dividing the WTP with the risk reduction. In order to derive estimates for the value of a statistical life (VSL) and severe injury risk (VSSI), we employ death-risk equivalents (Viscusi et al., 1991; Persson et al., 2001b). The death-risk equivalents (DRE) express non-fatal outcomes in units of death risks. Let $\Omega, r$, and $p$ denote the DRE, and the severe injury and fatality risk, respectively, then

$$
\Omega=\mathrm{VSSI} / \mathrm{VSL},
$$

and by assuming the the respondents' WTP is the sum of their WTP for each risk, VSL and VSSI can be derived as (Hultkrantz et al., 2006),

$$
\mathrm{VSL}=\mathrm{WTP} /(\Omega \Delta r+\Delta p)
$$

\footnotetext{
14 The variable High risk was dropped from the regressions since it created a perfect correlation in one of the subsamples.
} 
and

$$
\mathrm{VSSI}=\Omega \cdot \mathrm{VSL}
$$

In this study we use a DRE equal to 0.166, which is based on the official Swedish values used for BCA (SIKA, 2008). The risk reductions are per 100,000 and are based on the average numbers between 1993-1997, 3 fatalities and 16 severe injuries. In Table 7 we report the values for VSSA, VSL and VSSI for the private and public safety measures. Focusing on the VSL, the TB for the private safety measure is SEK 55.89 million which is 3 times as high as the WTP for the public safety measure. The parametric estimates are higher, but the ratio between the private and the public safety measure is lower, i.e. 1.7.

[Table 7 about here.]

\section{Discussion}

This study examines individuals' WTP for different safety devices and devices for different beneficiaries. Among other things, we find that WTP for a child is higher than private WTP, that WTP for a household is not higher than WTP for a single child, and that WTP for a private good is higher than for a public good. The results concerning child and public WTP are in line with other findings in the literature (Liu et al., 2000; Johannesson et al., 1996; de Blaeij et al., 2003).

The predominant assumption in the analysis of people's valuation of safety is that they are selfish. However, our results indicate that they are not purely selfish, but are prepared to pay for the safety of children, relatives and friends. Based on our findings it can be argued that the most likely form of nonselfish preferences is safety paternalism. However, we cannot reject the hypothesis that the respondents have pure altruistic or paternalistic preferences. When we do try to distinguish between the forms of altruistic preferences using the vouchers for the relatives, we can only conclude for $2.7-4.3$ percent of the sample that their altruistic preferences are strictly increasing in both wealth and safety (they were willing to change the safety device for a voucher), though. ${ }^{15}$ Our results would imply that individuals' paternalism is safety focused and that we should not ignore non-selfish preferences in BCA.

The result of the comparison between the private and public goods is not consistent with this conclusion of strong benevolence concerning safety. Given that people show strong concern for their relatives' and friends' safety we expect that safety for all people in Örebro (Q5 Public) is valued higher than private safety (Q1 Private) (Andersson, 2007a). That is not the case. For the public good the results imply

15 Our findings are in line with the findings of Jacobsson et al. (2007), who asked subjects to donate either money or nicotine patches to a smoking diabetes patient. When they asked those subjects who were willing to donate patches (41 percent) whether they would have donated more or less money, 19 percent said they would have donated the same amount (81 percent less). Thus, in their study 7.8 percent were prepared to dontate money instead of patches to the diabetes patient. 
that respondents are either wealth focused paternalists or pure altruists who believe that the project will reduce the welfare of others. Shogren (1990) showed that individuals may prefer private rather than public provision of safety. If people believe that public provision of safety will be inefficient they will favor the private alternative. Moreover, the results regarding non-selfish preferences might also have been influenced by "warm glow" (manifested in the act of giving instead of financing welfare anonymously through taxes) (Andreoni, 1989; Crumpler and Grossman, 2008) or "reciprocity" (individuals are willing to contribute to a public good if others also are willing to contribute) (Fehr and Gächter, 2000; Fehr and Fischbacher, 2002). Reciprocity implies, for instance, that individuals are not prepared to contribute to a public good if serious free riding is expected. Hence, both warm glow and reciprocity can explain the higher WTP for the safety of someone close to oneself (child or household member) compared with WTP for a public safety measure.

Hultkrantz et al. (2006) also estimated respondents' WTP to eliminate fatalities and severe injuries from road traffic in the city of Örebro. Their estimates are based on a parametric model and certainty calibration (Blumenschein et al., 2008), and were used to revise the official Swedish VSL to SEK 21 million (in 2006 price level, SIKA, 2008). Compared to their estimates of VSSA, VSL, and VSSI ours are close based on TB but higher using the parametric model. For instance, in 2006 price level, our estimates of private and public VSL using TB are SEK 62 and 20 million and based on the logit model SEK 92 and 53 million, whereas theirs were SEK 54 and 20 million. The usefulness of a direct comparison is limited, however, since the values in Hultkrantz et al. (2006), but not in our study, are based on certainty calibration. Since both Hultkrantz et al. (2006) and our survey asked respondents about a safety measure that would eliminate fatalities and severe injuries, estimates may be biased due to the certainty premium (Viscusi, 1989). The empirical support for a certainty premium is weak, however. The values of both studies are both higher and within the range of other Swedish CVM studies (Persson and Cedervall, 1991; Johannesson et al., 1996; Persson et al., 2001a; Johannesson et al., 1996; Andersson, 2007b).

In the survey we used a scenario where the safety devices would eliminate the risk of fatalities and severe injuries in road traffic. Even if the people of Örebro are familiar with Vision zero, since it has been given a lot of attention in the city and in Sweden, the credibility of the scenario presented in this study is a potential weakness of the survey. This together with the potential certainty premium, and the mixed results on the form of the respondents' altruistic preferences, means that we are not prepared to suggest that our VSL, VSSI, and VSSA estimates are used for policy purposes. Our results are, however, important from both a research and policy perspective; the findings in this study on the relationships between respondents' WTP for own safety, safety for others close to them and for the public therefore contribute to the understanding of people's altruistic preferences in road safety, and highlights 
the difficulty of eliciting preferences for private and public safety. Moreover, the reliability of the CVM in deriving a WTP to reduce health risks has been questioned. Serious problem with embedding, scope and framing effects have been found (Beattie et al., 1998; Hammitt and Graham, 1999). We believe that these problems are most severe when it comes to estimating policy values, such as the VSL, however, and hence not a problem for the purpose of this study. 


\section{References}

Andersson, H. and P. Lundborg: 2007, 'Perception of own death risk: An analysis of road-traffic and overall mortality risk'. Journal of Risk and Uncertainty 34(1), 67-84.

Andersson, H.: 2007a, 'Private and Public WTP for Safety - A Validity Test'. Working Paper 2007:14, VTI, Dept. of Transport Economics, Stockholm, Sweden.

Andersson, H.: 2007b, 'Willingness to Pay for Road Safety and Estimates of the Risk of Death: Evidence from a Swedish Contingent Valuation Study'. Accident Analysis and Prevention 39(4), 853-865.

Andreoni, J.: 1989, 'Impure Altruism and Donations to Public Goods: A Theory of Warm-Glow Giving'. Journal of Political Economy 97(6), 1447-1458.

Araña, J. E. and C. J. León: 2002, 'Willingness to pay for health risk reduction in the context of altruism'. Health Economics 11(7), 623-635.

Archibald, G. C. and D. Donaldson: 1976, 'Non-Paternalism and the Basic Theorems of Welfare Economics'. Canadian Journal of Economics 9(3), 492-507.

Ayer, M., H. D. Brunk, G. M. Ewing, W. T. Reid, and E. Silverman: 1955, 'An Empirical Distribution Function for Sampling with Incomplete Information'. Annals of Mathematical Statistics 26(4), 641647.

Bateman, I. J. and R. Brouwer: 2006, 'Consistency and construction in stated WTP for health risk reductions: A novel scope-sensitivity test'. Resource and Energy Economics 28(3), 199-214.

Bateman, I. J., R. T. Carson, B. Day, M. Hanemann, N. Hanley, T. Hett, M. Jones-Lee, G. Loomes, S. Mourato, Özdemiroḡlu, D. W. Pearce, R. Sugden, and J. Swanson: 2002, Economic Valuation with Stated Preference Techniques: A Manual. Cheltenham, UK: Edward Elgar.

Beattie, J., J. Covey, P. Dolan, L. Hopkins, M. W. Jones-Lee, G. Loomes, N. Pidgeon, A. Robinson, and A. Spencer: 1998, 'On the Contingnent Valuation of Safety and the Safety of Contingent Valuation: Part 1 - Caveat Investigator'. Journal of Risk and Uncertainty 17(1), 5-25.

Becker, G. S.: 1976, The Economic Approach to Human Behavior. Chicago, IL, USA: University of Chicago Press.

Bergstrom, T. C.: 1982, The Value of Life and Safety (Jones-Lee, M.W., ed.), Chapt. When is a man's life worth more than his human capital?, pp. 3-26. Amsterdam, Netherlands: North-Holland.

Bergstrom, T. C.: 2006, 'Benefit cost in a benevolent society'. American Economic Review 96(1), 339351.

Blumenschein, K., G. C. Blomquist, M. Johannesson, N. Horn, and P. Freeman: 2008, 'Eliciting Willingness to Pay without Bias: Evidence from a Field Experiment'. Economic Journal 118(525), 114-137.

Cameron, T. A.: 1988, 'A New Paradigm for Valuing Non-market Goods Using Referendum Data: Maximum Likelihood Estimation by Censored Logistic Regression'. Journal of Environmental Economics and Management 15, 355-379.

Carson, R. T. and W. M. Hanemann: 2005, Handbook of Environmental Economics: Valuing Environmental Changes, Vol. 2 of Handbook in Economics (Mäler, K.G., and Jeffrey, R.V., eds.), Chapt. Contingent Valuation, pp. 821-936. Amsterdam, the Netherlands: North-Holland, first edition.

Chanel, O., S. Luchini, and J. Shogren: 2005, 'Does charity begin at home for pollution reductions?'. Document de Travail 57, GREQAM.

Crumpler, H. and P. J. Grossman: 2008, 'An experimental test of warm glow giving'. Journal of Public Economics 92, 1011-1021.

de Blaeij, A., R. J. G. M. Florax, P. Rietveld, and E. Verhoef: 2003, 'The Value of Statistical Life in Road Safety: A Meta-Analysis'. Accident Analysis and Prevention 35(6), 973-986.

Dickie, M. and S. Gerking: 2007, 'Altruism and environmental risks to health of parents and their children'. Journal of Environmental Economics and Management 53(3), 323-341.

Dickie, M. and V. L. Messman: 2004, 'Parental altruism and the value of avoiding acute illness: are kids worth more than parents?'. Journal of Environmental Economics and Management 48(3), 1146-1174.

Fehr, E. and U. Fischbacher: 2002, 'Why social preferences matter - the impact of non-selfish motives on competition, cooperation and incentives'. Economic Journal 112(478), C1-C33.

Fehr, E. and S. Gächter: 2000, 'Fairness and Retaliation: The Economics of Reciprocity'. Journal of Economic Perspectives 14(3), 159-181.

Haab, T. C. and K. E. McConnel: 2003, Valuing Environmental and Natural Resources: The Econometrics of Non-Market Valuation. Cheltenham, UK: Edward Elgar. 
Hakes, J. K. and W. K. Viscusi: 2004, 'Dead Reckoning: Demographic Determinants of the Accuracy of Mortality Risk Perception'. Risk Analysis 24(3), 651-664.

Hammitt, J. K. and J. D. Graham: 1999, 'Willingness to Pay for Health Protection: Inadequate Sensitivity to Probability?'. Journal of Risk and Uncertainty 18(1), 33-62.

Hanemann, M. and B. Kanninen: 1999, Valuing Environmental Preferences: Theory and Practice of the Contingent Valuation Method in the US, EU, and Developing Countries (Bateman, I.J, and Willis, K.G., eds.), Chapt. The Statistical Analysis of Discrete-Response CV Data, pp. 302-441. Oxford, UK: Oxford University Press.

Hanemann, W. M.: 1984, 'Welfare Evaluations in Contingent Valuation Experiments with Discrete Responses'. American Journal of Agricultural Economics 66(3), 332-341.

Holmes, T. P.: 1990, 'Self-Interest, Altruism, and Health-Risk Reduction: An Economic Analysis of Voting Behavior'. Land Economics 66(2), 140-149.

Hultkrantz, L., G. Lindberg, and C. Andersson: 2006, 'The Value of Improved Road Safety'. Journal of Risk and Uncertainty 32(2), 151-170.

Jacobsson, F., M. Johannesson, and L. Borgquist: 2007, 'Is altrusim paternalistic?'. Economic Journal 117, 761-781.

Johannesson, M., P.-O. Johansson, and R. M. O'Connor: 1996, 'The Value of Private Safety Versus the Value of Public Safety'. Journal of Risk and Uncertainty 13(3), 263-275.

Johansson, P.-O.: 1995, Evaluating Health Risks: An Economic Approach. Cambridge, UK: Cambridge University Press.

Jones-Lee, M. W.: 1976, The Value of Life: An Economic Analysis. London, UK: Martin Robertsson.

Jones-Lee, M. W.: 1991, 'Altruism and the Value of Other People's Safety'. Journal of Risk and Uncertainty 4, 213-219.

Jones-Lee, M. W.: 1992, 'Paternalistic Altruism and the Value of Statistical Life'. Economic Journal 102(410), 80-90.

Kahneman, D., P. Slovic, and A. Tversky: 1982, Judgement under Uncertainty: Heuristics and Biases. New York, NY, USA: Cambridge University Press.

Kahneman, D. and A. Tversky: 1979, 'Prospect Theory: An Analysis of Decision Under Risk'. Econometrica 47(2), 263-291.

Leung, J. and J. Guria: 2006, 'Value of statistical life: Adults versus children'. Accident Analysis and Prevention 38(6), 1208-1217.

Lindberg, G.: 2006, 'Valuation and Pricing of Traffic Safety'. Ph.D. Thesis, Örebro Studies in Economics 13, Dept. of Economics, Statistics and Informatics, Örebro University, Örebro, Sweden.

Liu, J.-T., J. K. Hammitt, J.-D. Wang, and J.-L. Liu: 2000, 'Mohter's Willingness to Pay for Her Own and Her Child's Health: A Contingent Valuation Study in Taiwan'. Health Economcis 9(4), 319-326.

Mishan, E. J.: 1971, 'Evaluation of Life and Limb: A Theoretical Approach'. Journal of Political Economy 79(4), 687-705.

Mitchell, R. C. and R. T. Carson: 1989, Using Surveys to Value Public Goods. Resources for the Future.

Needleman, L.: 1976, 'Valuing Other People's Lives'. Manchester School of Economic E Social Studies 44(4), 309-342.

Persson, S. and E. Lindqvist: 2003, 'Värdering av tid, olyckor och miljö vid vägtrafikinvesteringar Kartläggning och modellbeskrivning'. Rapport 5270, Naturvårdsverket (The Swedish Environmental Protection Agency), Stockholm, Sweden.

Persson, U. and M. Cedervall: 1991, 'The Value of Risk Reduction: Results of a Swedish Sample Survey'. IHE Working Paper 1991:6, The Swedish Institute for Health Economics.

Persson, U., A. Norinder, K. Hjalte, and K. Gralén: 2001a, 'The Value of a Statistical Life in Transport: Findings from a new Contingent Valuation Study in Sweden'. Journal of Risk and Uncertainty 23(2), 121-134.

Persson, U., A. Trawén, A. Norinder, K. Hjalte, and H. Andersson: 2001b, 'Relative Risk Values of Non-Fatal Traffic Injuries - A Comparison Between Contingent Valuation, Risk-Risk Trade Off and Standard Gamble Methods'. Swiss Journal of Economics and Statistics 137(1), 117-128.

Prop. 1997/98:56: 1998, 'Government bill 1997/98:56: Transportpolitik för en hållbar utveckling'. Government bill by the Swedish Government.

Sen, A.: 1987, On Ethics and Economics. Oxford, UK: Basil Blackwell. 
Shogren, J. F.: 1990, 'The Impact of Self-protection and Self-insurance on Individual Response to Risk'. Journal of Risk and Uncertainty 3, 191-204.

SIKA: 2008, 'Samhällsekonomiska principer och kalkylvärden för transportsektorn: ASEK 4'. Pm 2008:3, SIKA (Swedish Institute for Transport and Communications Analysis), Östersund, Sweden.

Turnbull, B. W.: 1976, 'The Empirical Distribution Function with Arbitrarily Grouped, Censored, and Truncated Data'. Journal of the Royal Statistical Society 38(B), 290-295.

Varian, H. R.: 1992, Microeconomic Analysis. New York, NY, USA: W. W. Norton \& Company, third edition.

Vázquez Rodríguez, M. X. and C. J. León: 2004, 'Altruism and the Economic Values of Environmental and Social Policies'. Environmental and Resource Economics 28(2), 233-249.

Viscusi, W. K., W. A. Magat, and A. Forrest: 1988, 'Altruistic and Private Valuations of Risk Reduction'. Journal of Policy Analysis and Management 7(2), 227-245.

Viscusi, W. K., W. A. Magat, and J. Huber: 1991, 'Pricing Environmental Health Risks: Aurvey Assessments of Risk-risk and Risk-Dollar Trade-Offs for Chronic Bronchitis'. Journal of Environmental Economics and Management 21(1), 32-51.

Viscusi, W. K.: 1989, 'Prospective Reference Theory: Toward an Explanation of the Paradoxes'. Journal of Risk and Uncertainty 2(3), 235-263. 


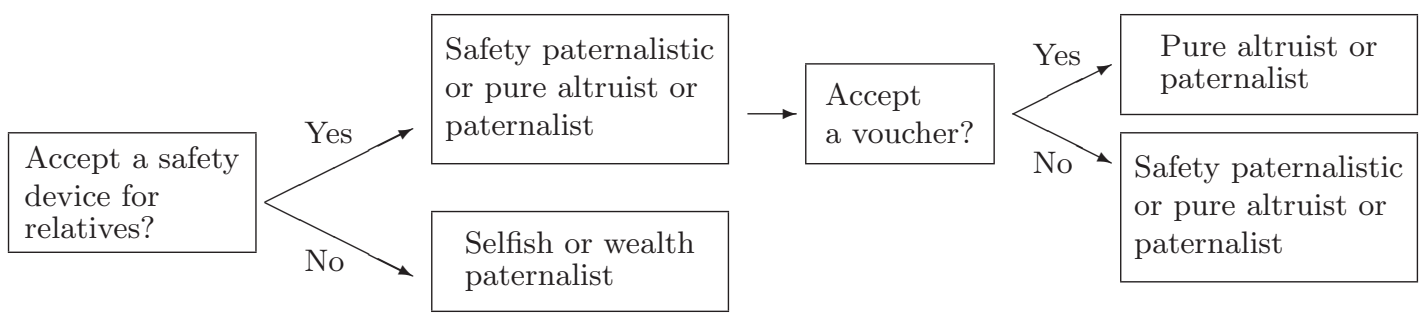

Fig. 1 The chosen questionnaire scheme for relative's safety

Table 1 Subsamples of the survey

\begin{tabular}{|c|c|c|c|c|}
\hline Subsample & Question & $\begin{array}{l}\text { Sample } \\
\text { size }\end{array}$ & $\begin{array}{c}\text { Non- } \\
\text { response }^{a}\end{array}$ & Completed $^{\mathrm{b}}$ \\
\hline Q1 Private & WTP private safety measure. & 390 & $162(12)$ & $216(57 \%)$ \\
\hline Q2 Child & WTP to reduce child's risk. & 390 & $170(4)$ & $206(54 \%)$ \\
\hline Q3 Household ${ }^{\mathrm{c}}$ & $\begin{array}{l}\text { 1. WTP household. } \\
\text { 2. WTP relative. } \\
\text { 3. Voucher relative. }\end{array}$ & 390 & $179(9)$ & $202(53 \%)$ \\
\hline Q4 Relative ${ }^{\mathrm{c}}$ & $\begin{array}{l}\text { 1. WTP relative. } \\
\text { 2. Voucher relative. }\end{array}$ & 390 & $185(10)$ & $195(51 \%)$ \\
\hline Q5 Public & WTP for public safety measure. & 390 & $159(9)$ & $222(58 \%)$ \\
\hline TOTAL & & 1950 & $855(44)$ & $1040(55 \%)$ \\
\hline
\end{tabular}




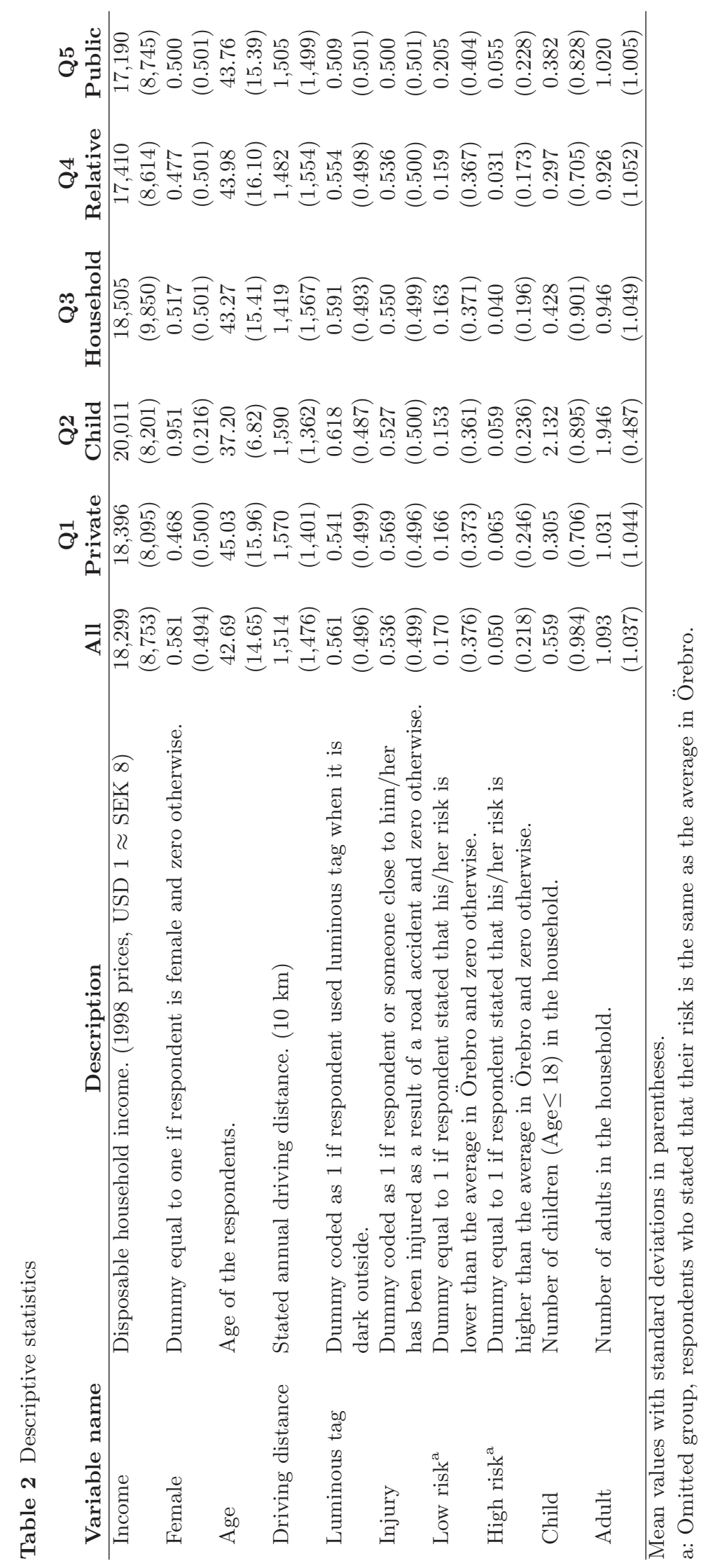


Table 3 Probabilities of accepting bids

\begin{tabular}{rccccccccc}
\hline & Q1 & Q2 & \multicolumn{3}{c}{ Q3 Household } & & Q4 Relative & Q5 \\
Bid & Private & Child & Household $^{\text {a }}$ & Safety & Voucher & Safety & Voucher & Public \\
\hline 200 & 0.658 & 0.861 & 0.667 & 0.410 & 0.250 & & 0.605 & 0.217 & 0.535 \\
1000 & 0.679 & 0.704 & 0.533 & 0.300 & 0.111 & & 0.269 & 0.000 & 0.297 \\
2000 & 0.290 & 0.571 & 0.351 & 0.216 & 0.000 & & 0.235 & 0.286 & 0.172 \\
5000 & 0.163 & 0.382 & 0.212 & 0.121 & 0.000 & & 0.111 & 0.000 & 0.132 \\
10000 & 0.083 & 0.324 & 0.081 & 0.027 & 0.000 & & 0.121 & 0.000 & 0.027 \\
20000 & 0.147 & 0.207 & 0.074 & 0.000 & 0.000 & & 0.000 & 0.000 & 0.000 \\
\hline
\end{tabular}

a: The bid levels when asked about household safety were twice the size of the bids in column one.

Table 4 Number of demanded safety devices for relatives.

\begin{tabular}{|c|c|c|c|c|c|c|c|c|}
\hline \multirow[b]{2}{*}{$\mathrm{Bid}^{\mathrm{b}}$} & \multicolumn{4}{|c|}{ Q3 Household Ha $^{\text {a }}$} & \multicolumn{4}{|c|}{ Q4 Relative R $^{\text {a }}$} \\
\hline & 1 & 2 & $3-11$ & $>11$ & 1 & 2 & $3-11$ & $>11$ \\
\hline 200 & 7 & 5 & 4 & 0 & 6 & 8 & 9 & 0 \\
\hline 1000 & 2 & 1 & 5 & 1 & 4 & 2 & 1 & 0 \\
\hline 2000 & 6 & 1 & 1 & 0 & 5 & 3 & 0 & 0 \\
\hline 5000 & 1 & 2 & 0 & 1 & 3 & 1 & 0 & 0 \\
\hline 10000 & 0 & 0 & 1 & 0 & 2 & 0 & 2 & 0 \\
\hline Proportion $^{\mathrm{c}}$ & 0.42 & 0.24 & 0.29 & 0.05 & 0.43 & 0.30 & 0.26 & 0 \\
\hline
\end{tabular}

Table 5 Non-parametric and parametric mean WTP

\begin{tabular}{|c|c|c|c|c|c|c|}
\hline & \multirow{2}{*}{$\begin{array}{c}\text { Q1 } \\
\text { Private }\end{array}$} & \multirow{2}{*}{$\begin{array}{c}\text { Q2 } \\
\text { Child }\end{array}$} & \multicolumn{2}{|c|}{ Q3 Household } & \multirow{2}{*}{$\begin{array}{c}\text { Q4 } \\
\text { Relative }\end{array}$} & \multirow{2}{*}{$\begin{array}{c}\text { Q5 } \\
\text { Public }\end{array}$} \\
\hline & & & Household & Relative & & \\
\hline \multicolumn{7}{|l|}{ Turnbull } \\
\hline$\overline{\text { Mean WTP }}$ & $3,161^{\mathrm{d}}$ & 6,144 & 5,388 & 1,037 & $1,499^{\mathrm{d}}$ & 1,047 \\
\hline Ratio $^{\mathrm{a}}$ & - & 1.944 & 1.704 & 0.328 & 0.474 & 0.331 \\
\hline t-value ${ }^{b}$ & - & 4.14 & 2.54 & 3.13 & 2.59 & 3.12 \\
\hline \multicolumn{7}{|l|}{ Parametric } \\
\hline$\overline{\text { Mean WTP }}$ & 4,712 & 15,638 & 8,440 & 1,582 & 2,495 & $2,696^{\mathrm{e}}$ \\
\hline Ratio $^{a}$ & - & 3.319 & 1.791 & 0.336 & 0.530 & 0.572 \\
\hline C.I. ${ }^{\mathrm{c}}$ : Lower & 2,660 & 7,844 & 4,135 & 505 & 1,010 & 1,086 \\
\hline Upper & 7,776 & 29,768 & 14,210 & 2,680 & 4,043 & 4,763 \\
\hline
\end{tabular}

a: Ratio between WTP for the different subsamples and Q1 Private.

b: t-value for difference in mean estimates between Q1 Private and corresponding subsample.

c: $95 \%$ confidence intervals. (Bootstrap, 5,000 replications.)

d: PAVA used to estimate WTP since probability vector non-monotonic (Ayer et al., 1955).

e: Mean WTP for the Q5 Public was estimated ruling out negative WTP. Allowing for negative WTP reveal the same qualitative relationship between Q1 and Q5. 
Table 6 Multivariate WTP regression

\begin{tabular}{lcc}
\hline \multicolumn{1}{c}{ Variable } & Coefficient & (Std. Err.) \\
\hline Q2 Child & $7374.62^{* *}$ & $(1802.29)$ \\
Q3 Household & $2701.37^{\dagger}$ & $(1562.41)$ \\
Q4 Relative & $-3834.61^{*}$ & $(1618.08)$ \\
Q5 Public & $-3408.39^{*}$ & $(1570.54)$ \\
Income $^{\mathrm{a}}$ & $290.95^{* *}$ & $(70.19)$ \\
Female $_{\text {Age }}-1814.88$ & $(1154.23)$ \\
Driving distance & 24.53 & $(38.69)$ \\
Luminous tag & -0.37 & $(0.39)$ \\
Injury & $3712.99^{* *}$ & $(1049.98)$ \\
Low risk & $-3629.26^{* *}$ & $(1034.47)$ \\
Child & -398.30 & $(567.57)$ \\
Adult & $-1927.01^{\dagger}$ & $(1014.50)$ \\
Intercept & -2826.77 & $(2821.74)$ \\
\hline N & \multicolumn{3}{c}{942} \\
Pseudo R & \multicolumn{3}{c}{0.21} \\
\hline Significance levels : $\dagger: 10 \%$ & $*: 5 \%$ \\
a: Household income per 1,000 SEK.
\end{tabular}

Table 7 Value of statistical cases in million SEK

\begin{tabular}{|c|c|c|c|c|c|c|}
\hline & \multicolumn{3}{|c|}{ Turnbull } & \multicolumn{3}{|c|}{ Parametric } \\
\hline & VSSA & VSL & VSSI & VSSA & VSL & VSSI \\
\hline Private & 16.64 & 55.89 & 8.61 & 24.80 & 83.31 & 13.98 \\
\hline Public & 5.51 & 18.51 & 2.85 & 14.19 & 47.67 & 7.91 \\
\hline $\begin{array}{l}\mathrm{VSSA}= \\
\text { Death ri } \\
\text { Risk cha } \\
\Delta \pi=19\end{array}$ & $\begin{array}{l}T P / \Delta \\
\text { equiv } \\
\text { es per } \\
\text { (ii) mo }\end{array}$ & $\begin{array}{l}\text {, VSL= } \\
\text { ent, } \Omega \\
\text { l00,000 } \\
\text { pidity, }\end{array}$ & $\begin{array}{l}W T P / \\
=0.154 \\
\text { (i) seve }\end{array}$ & $2 \Delta r-$ & $p), \mathrm{V}$ & $\Omega \cdot \mathrm{VS}$ \\
\hline
\end{tabular}

